\title{
The effect of carnitine on liver regeneration after partial hepatectomy
}

\author{
Parlak $\mathrm{O}^{1}$, Sisman $\mathrm{CI}^{1}$, Ucar $\mathrm{AE}^{1}$, Kusdemir $\mathrm{A}^{1}$, Yalcin $\mathrm{S}^{2}$ \\ Ankara Ataturk Education and Research Hospital Department of 2nd General Surgery, Ankara, Turkey. \\ sametyalcin71@yahoo.com
}

\begin{abstract}
Aim: The role of carnitine in liver regeneration. Can carnitine given externally increase and/or fasten the beginning of liver regeneration?

Results: Wistar Albino rats were used. Group 1: The group, which was applied parenteral carnitine after partial hepatectomy and sacrificed on the 1st day. Group 2: The group, which was applied parenteral carnitine after partial hepatectomy and sacrificed on the 7th day. Group 3: The group, which wasn't applied parenteral carnitine after partial hepatectomy and sacrificed in the 1st day. Group 4: The group which wasn't applied parenteral carnitne after partial hepatectomy and sacrificed on the 7th day. To all the rats, partial liver resection with the rate of $70 \%$ was applied. Being started shortly after the resection, $100 \mathrm{mg} / \mathrm{kg} / \mathrm{day}$ parenteral L-carnitine was applied to the first and second group. On the 1st and 7th days after the resection, eight subjects from each group were sacrificed. To evaluate the liver regeneration Ki-67 monoclonal antibody was used.

After the examinations carried out by pathological clinic, detected mitosis number were examined. The 1 st and 7th day mitosis number of the rats taken into the study was seen as statistically significantly higher than the mitosis number of the rats in the control group.

Conclusions: As a result, among the rats, which were applied hepatectomy, if met by the major conditions triggering liver regeneration following the external carnitine supplementation, we can say with the help of the information provided by the study measuring the regeneration capacity by analysing Ki-67 proliferation index, that external carnitine support can increase the capacity of regeneration if it is given in appropriate dose (Tab. 6, Fig. 7, Ref. 17). Text in PDF www.elis.sk. Key words: hepatectomy, regeneration, carnitine.
\end{abstract}

Research ethics committee approval was received from the Gazi University. And then, in the same university's Raising Laboratory Animals and Experimential Researchs Center (GUERM), this study was carried out. Wistar Albino rats, whose weights were 200-250g and feeding with the laboratory feed, were used. These rats were in eight-ten weeks and their lives were maintained in fours cages, at room temperature, with creating 12 hour daylightdarkness cycle, feeding with normal water and proper diet. Four groups, which each of them contained 8 rats, were taken into the research. The groups:

Group 1: The group, which was applied parenteral carnitine after partial hepatectomy and sacrificed in the 1st day.

Group 2: The group, which was applied parenteral carnitine after partial hepatectomy and sacrificed in the 7 th day.

Group 3: The group which wasn't applied parenteral carnitine after partial hepatectomy and sacrificed in the 1st day.

${ }^{1}$ Ankara Ataturk Education and Research Hospital Department of 2nd General Surgery, Ankara, Turkey, and ${ }^{2}$ Ankara Yildirim Beyazit University, Faculty of Medicine, Ankara Ataturk Education and Research Hospital Department of General Surgery, Ankara, Turkey

Address for correspondence: S. Yalcin, MD, Batikent Kardelen District, 2091 Street, Emek Housins Estate, No: 31 TR-06370, YenimahalleAnkara-Turkey.

Phone: +90.312 .2912525$
Group 4: The group, which wasn't applied parenteral carnitne after partial hepatectomy and sacrificed in the 7th day.

Group 1 and Group 2 were the study groups and Group 3 and Group 4 were the control group. Operations were performed in the first half of the day in order to pretend the effect of daily changing regenerative response. By providing sterile conditions, after abdominal shaving of the rats under the $40 \mathrm{mg} / \mathrm{kg}$ Ketamine HCL (Ketas) anaesthesia, laparotomy was performed by midline incision with $2.5 \mathrm{~cm}$.

$70 \%$ hepatectomy was performed by tying liver left lateral and median lobs pedicules with 4/0 silk as Higgins and Anderson define $(1,2)$. This method was preferred because of the advantages of it that is an easy performing feature and remained liver tissue was non-damaged. Received tissue samples (Fig. 1) were detected for the histopathological examination in the $10 \%$ tamponed formal. Laparatomy incisions of all the rats were taped with two line continuous sutures by using $4 / 0$ silk. Beginning shortly after the $70 \%$ liver resection, while $100 \mathrm{mg} / \mathrm{kg}$ /day L-Karnitine was being given to first and second group as intraperitoneal, $0,5 \mathrm{cc}$ serum was given to third and forth groups as physiological intraperitional. After the liver resection, eight subjects from each group were sacrified in 1st and 7th days. Shortly before the death, intracardiac blood samples were taken from the subjects for biochemical analyses. AST, ALT determinations in the blood samples was carried out in the biochemistry laboratory of our hospital. 

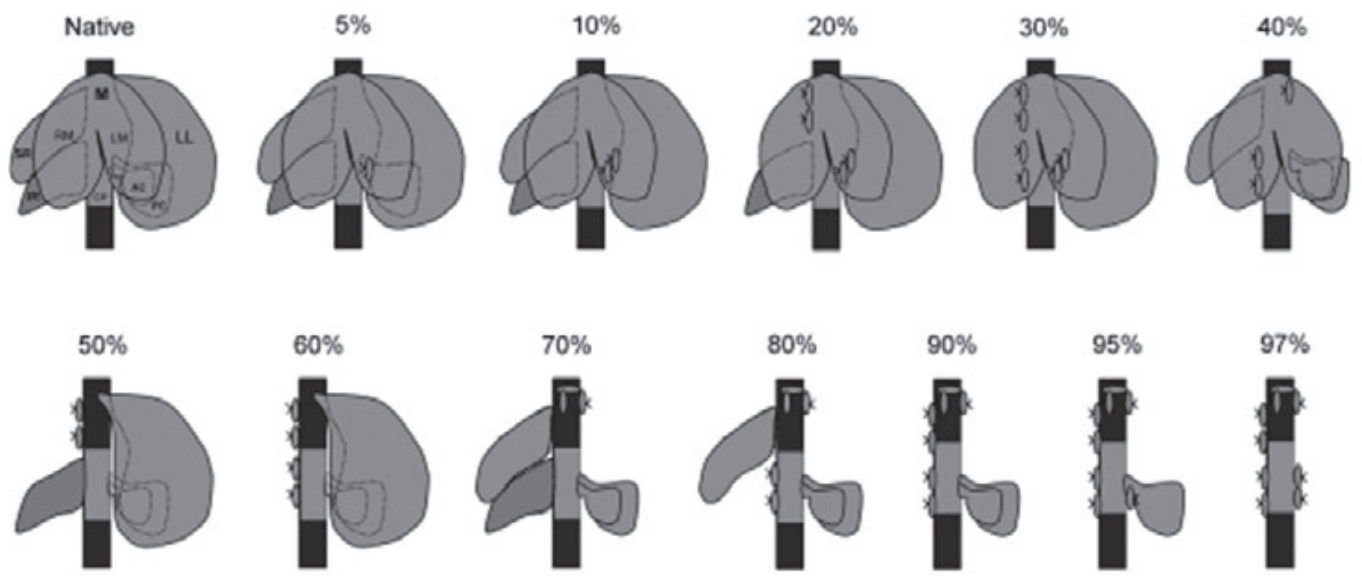

Fig. 1. Schematic presentation of the partial hepatectomy and approximate parenchymal liver volume in the rats (frontal view of the liver) (2).

\section{Biochemical analysis}

In the blood samples of all the rats, which were taken as intracardiac, the levels of ALT, AST, Albumin and Total Bilirubin were measured in the biochemistry laboratory of Ankara Atatürk Training and Research Hospital.

\section{Immunohistochemical assessment}

Immunohistochemical assessment was carried out in the pathology laboratory of Ankara Atatürk Training and Research hos-

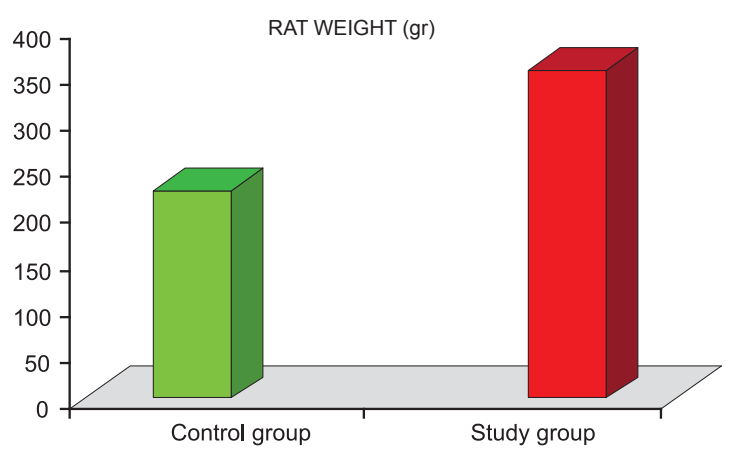

Fig. 2. 1st day the weights of the rats in control and study groups.

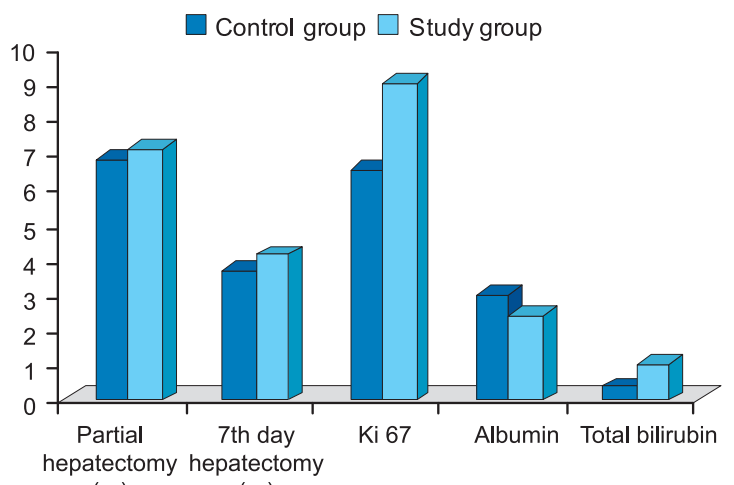

(gr)

(gr)

Fig. 3. 1st day comparison of the parameters of the rats (below). pital. Received tissue samples were detected for the histopathological examination in $10 \%$ tamponed formal.

In the case, which had been taken into the study, in order to define Ki-67 expression, incisions were prepared as 4 micrometer thickness paraffin blocks incisions taken into the lams with PolyL-lysine. Ki-67 (SP6) ready to use rabbit monoclonal antibody and Immunohistochemical staining procedure was practiced.

While Ki-67 staining pattern being assessed, Wintzer's method was used (3). On the assessed lams, 200 and 500 cells were

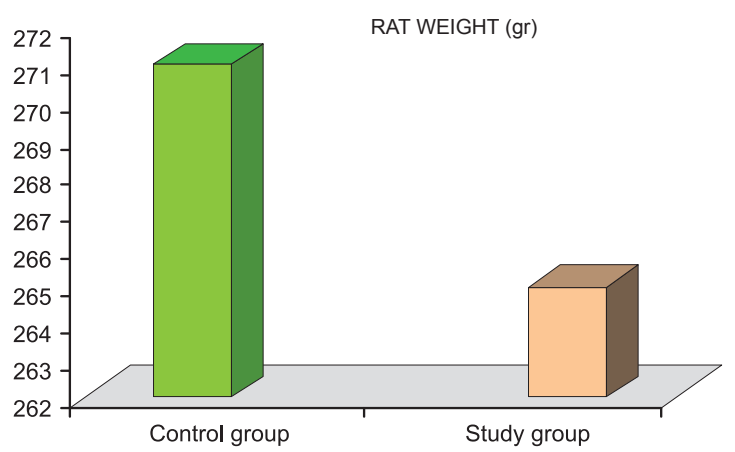

Fig. 4. 7th day the weights of the rats in the control and study groups.

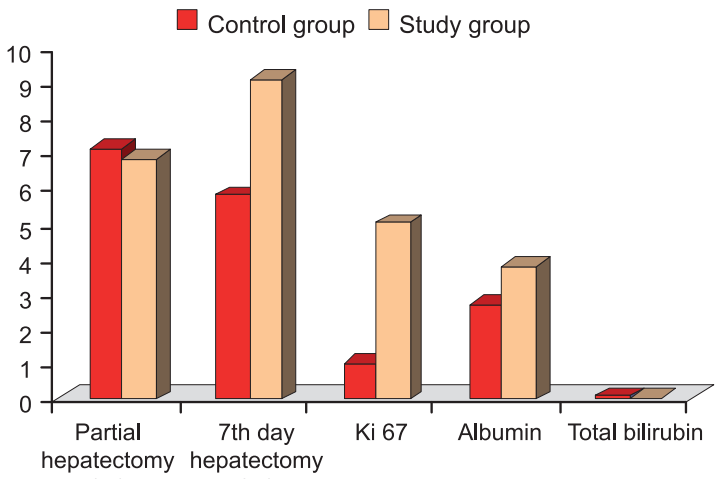

(gr)

(gr)

Fig. 5. 7th day comparison of the parameters belongs to the rats in the groups. 
Tab. 1. Data belongs to rats from the control group performed hepatectomy in 1st day.

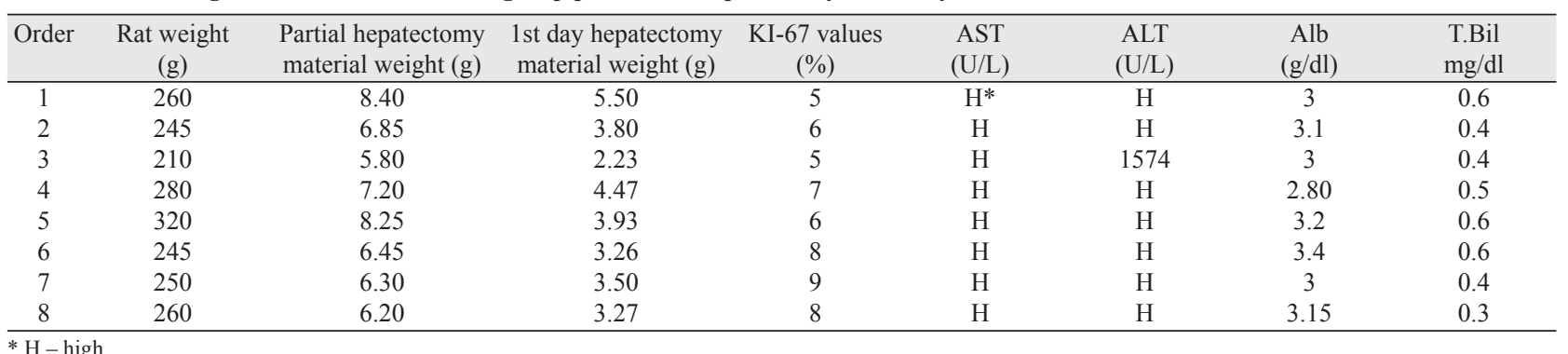

Tab. 2. Data belongs to rats from the control group performed hepatectomy in 7 th day.

\begin{tabular}{|c|c|c|c|c|c|c|c|c|}
\hline Order & $\begin{array}{c}\text { Rat weight } \\
\text { (g) }\end{array}$ & $\begin{array}{l}\text { Partial hepatectomy } \\
\text { material weight }(\mathrm{g})\end{array}$ & $\begin{array}{l}\text { 1st day hepatectomy } \\
\text { material weight }(\mathrm{g})\end{array}$ & $\begin{array}{c}\text { KI-67 values } \\
(\%)\end{array}$ & $\begin{array}{l}\text { AST } \\
(\mathrm{U} / \mathrm{L})\end{array}$ & $\begin{array}{c}\text { ALT } \\
(\mathrm{U} / \mathrm{L})\end{array}$ & $\begin{array}{c}\text { Alb } \\
(\mathrm{g} / \mathrm{dl})\end{array}$ & $\begin{array}{l}\text { T.Bil } \\
\mathrm{mg} / \mathrm{dl}\end{array}$ \\
\hline 1 & 450 & 8.4 & 8.80 & 1 & 312 & 206 & 2.2 & 0.1 \\
\hline 2 & 420 & 9.1 & 9.87 & 2 & 172 & 103 & 2.6 & 0 \\
\hline 3 & 272 & 8.6 & 11.4 & 0 & 192 & 120 & 2.9 & 0.1 \\
\hline 4 & 257 & 5.8 & 7.06 & 1 & 299 & 188 & 2.5 & 0.1 \\
\hline 5 & 270 & 6.2 & 3.43 & 1 & $\mathrm{H}^{*}$ & $\mathrm{H}$ & 2.8 & 1.1 \\
\hline 6 & 260 & 5.9 & 3.54 & 2 & $\mathrm{H}$ & $\mathrm{H}$ & 2.2 & 1 \\
\hline 8 & 245 & 5.4 & 4.25 & 1 & $\mathrm{H}$ & 1080 & 2.3 & 0.1 \\
\hline
\end{tabular}

Tab. 3. Data belongs to rats from the study group performed hepatectomy in 1st day.

\begin{tabular}{|c|c|c|c|c|c|c|c|c|}
\hline Order & $\begin{array}{c}\text { Rat weight } \\
\text { (g) }\end{array}$ & $\begin{array}{l}\text { Partial hepatectomy } \\
\text { material weight }(\mathrm{g})\end{array}$ & $\begin{array}{l}\text { 1st day hepatectomy } \\
\text { material weight }(\mathrm{g})\end{array}$ & $\begin{array}{c}\text { KI-67 values } \\
(\%)\end{array}$ & $\begin{array}{l}\text { AST } \\
(\mathrm{U} / \mathrm{L})\end{array}$ & $\begin{array}{c}\text { ALT } \\
(\mathrm{U} / \mathrm{L})\end{array}$ & $\begin{array}{l}\text { Alb } \\
(\mathrm{g} / \mathrm{dl})\end{array}$ & $\begin{array}{l}\text { T.Bil } \\
\mathrm{mg} / \mathrm{dl}\end{array}$ \\
\hline 1 & 354 & 7.4 & 4.47 & 12 & $\mathrm{H}$ & $\mathrm{H}$ & 3.1 & 1.3 \\
\hline 2 & 397 & 6.73 & 3.93 & 14 & $\mathrm{H}$ & $\mathrm{H}$ & 2.3 & 1.1 \\
\hline 3 & 384 & 9.34 & 5.26 & 9 & $\mathrm{H}$ & $\mathrm{H}$ & 2.4 & 0.3 \\
\hline 4 & 460 & 9.15 & 5.50 & 7 & $\mathrm{H}$ & 1696 & 2.4 & 0.3 \\
\hline 5 & 270 & 6.4 & 3.27 & 9 & $\mathrm{H}$ & $\mathrm{H}$ & 3 & 1.2 \\
\hline 6 & 260 & 5.7 & 3.74 & 10 & $\mathrm{H}$ & $\mathrm{H}$ & 2.4 & 1 \\
\hline 8 & 245 & 5.15 & 4.0 & 7 & $\mathrm{H}$ & 1152 & 2.4 & 0.1 \\
\hline
\end{tabular}

Tab. 4. Data belongs to rats from the study group performed hepatectomy in 7th day.

\begin{tabular}{|c|c|c|c|c|c|c|c|c|}
\hline Order & $\begin{array}{c}\text { Rat weight } \\
(\mathrm{g})\end{array}$ & $\begin{array}{l}\text { Partial hepatectomy } \\
\text { material weight }(\mathrm{g})\end{array}$ & $\begin{array}{l}\text { 1st day hepatectomy } \\
\text { material weight }(\mathrm{g})\end{array}$ & $\begin{array}{c}\text { KI-67 values } \\
(\%)\end{array}$ & $\begin{array}{l}\text { AST } \\
(\mathrm{U} / \mathrm{L})\end{array}$ & $\begin{array}{l}\text { ALT } \\
(\mathrm{U} / \mathrm{L})\end{array}$ & $\begin{array}{c}\text { Alb } \\
(\mathrm{g} / \mathrm{dl})\end{array}$ & $\begin{array}{l}\text { T.Bil } \\
\mathrm{mg} / \mathrm{dl}\end{array}$ \\
\hline 1 & 250 & 6.23 & 10.7 & 5 & 574 & 329 & 2.6 & 0.1 \\
\hline 2 & 274 & 6.92 & 6.82 & 4 & 250 & 145 & 3 & 0.1 \\
\hline 3 & 270 & 6.40 & 11.5 & 6 & 149 & 99 & 2.7 & 0 \\
\hline 4 & 280 & 7.2 & 7.60 & 5 & 139 & 39 & 2.7 & 0 \\
\hline 5 & 320 & 8.18 & 11.15 & 7 & 208 & 110 & 2.8 & 0 \\
\hline 6 & 245 & 6.85 & 7.78 & 4 & 221 & 89 & 2.8 & 0.1 \\
\hline 8 & 260 & 6.3 & 9.4 & 5 & 136 & 78 & 2.6 & 0.1 \\
\hline
\end{tabular}

counted in the field of 200 and 400 big rate of growth. When immunohistochemical staining was being assessed, nuclear staining was considered and 10 thousand hepatocyt Ki-67 and cell number showing nuclear staining was determined.

\section{Statistical analysis}

In the assessment of the data provided in the study, SPSS FOR Windows 16. 0 (SPSS 16. 0 Inc Chicago, IL) statistic packet programs were used. Whether numeric data respect to normal distribution or not was assessed with Shapiro-Wilk test. Cases defined as minimum, middle, and maximum values.
For the inter-group comparison, the Mann-Whitney U analysis and for the paired comparison the Wilcoxon Signed Rank tests were used.

In the categorical variables comparison, crosstab statistics were used (Chi-square and Mc Nemar). The limit of statistically significance was determined as (p) 0.05 .

\section{Findings}

Results of laboratory

Follow-up outcome of 32 rats with performed partial hepatectomy during the experimental study, results which were provided 
Tab. 5. Comparison of the case parameters in the control and study groups.

\begin{tabular}{lccc}
\hline & Control group & Study group & $\mathrm{p}$ \\
\hline Rat weight $(\mathrm{g})$ & $255(210-320)$ & $357(245-460)$ & 0.027 \\
\hline $\begin{array}{l}\text { Partial hepatectomy } \\
\text { material Weight }(\mathrm{g})\end{array}$ & $6.65(5.8-8.4)$ & $7.065(5.15-9.34)$ & 0.600 \\
\hline $\begin{array}{l}\text { 1st day hepatectomy } \\
\text { material Weight }(\mathrm{g})\end{array}$ & $3.65(2.23-5.5)$ & $4.235(3.27-5.5)$ & 0.140 \\
\hline KI-67 Values $(\%)$ & $6.5(5-9)$ & $9(7-14)$ & 0.020 \\
\hline Albumin $(\mathrm{g} / \mathrm{dl})$ & $3.05(2.8-3.4)$ & $2.4(2.3-3.1)$ & 0.016 \\
\hline Total bilirubin $(\mathrm{mg} / \mathrm{dl})$ & $0.45(0.3-0.6)$ & $1(0.1-1.3)$ & 0.340 \\
\hline
\end{tabular}

Tab. 6. Comparison of case parameters in the control and study groups.

\begin{tabular}{lccc}
\hline & Control group & Study group & $\mathrm{p}$ \\
\hline Rat weight $(\mathrm{g})$ & $271(245-450)$ & $265(245-320)$ & 0.371 \\
\hline $\begin{array}{l}\text { Partial hepatectomy } \\
\text { Material weight }(\mathrm{g})\end{array}$ & $7.25(5.4-9.1)$ & $6.625(6-8.18)$ & 0.916 \\
\hline $\begin{array}{l}\text { 1st day hepatectomy } \\
\text { material weight }(\mathrm{g})\end{array}$ & $5.655(3.43-11.4)$ & $9.155(6.82-11.5)^{*}$ & 0.093 \\
\hline Ki-67 values $(\%)$ & $1(0-2)^{*}$ & $5(4-7)^{*}$ & 0.001 \\
\hline Albumin $(\mathrm{g} / \mathrm{dl})$ & $2.55(2.2-3)^{*}$ & $2.75(2.6-3)^{*}$ & 0.242 \\
\hline Total Bilirubin $(\mathrm{mg} / \mathrm{dl})$ & $0.1(0-1.1)$ & $0.05(0-0.1)^{*}$ & 0.040 \\
\hline *significant difference between 1st and 7th Day & &
\end{tabular}

by the experiment of liver tissues and blood samples taken on the 1 st and 7th experiment days in the pathology and biochemistry laboratory of our hospital are shown on the Figures 2-5 below. In the Tables 1-6, the outcomes of the study and control groups are listed separately.

The weights of the rats in the control group were seen as statistically significantly lower than the rats in the study group $(p=0.027)$. This difference is related to the following condition; when the groups were created in the beginning of the experiment, it was planned deliberately that the rats which had much weight considered as stronger in post-operation process. There was no statistically significant difference between the materials of weights provided by partial hepatectomies which was performed in the beginning of the experiment on the 0th day and the materials of weights provided by post supplementary hepatectomies performed on the 1 st day (respectively $p=0.600$ and $p=0.140$ ).

When the mitosis numbers examined behind the research of the pathology, the mitosis number of the rats taken into the study group on the 1st day was determined as statistically significantly higher than the mitosis number of the rats in the control group $(\mathrm{p}=$ 0.020) (Figs 6 and 7).

When the plasma albumin levels of the cases were compared, it was seen that the rats in the control group were statistically significantly higher than the rats in the study group $(p=0.016)$. In respect of total bilirubin levels, there was no statistically significant difference between the groups $(p=0.340)$. When the 7 th day findings of the rats in the study and control group were compared, it could be seen that there was no statistically significant difference between the groups in terms of the weight of the rats, the weight of the partial hepatectomy materials, the weight of 7 th day hepatectomy materials and levels of albumin. The mitosis number of the cases in the study group was statistically significantly higher than the mitosis number of the cases in the control group $(p=0.001)$. In respect of bilirubin values, the total bilirubin of the cases in the study group was statistically significantly lower than the total bilirubin of the cases in the control group $(p=0.040)$.

In the consequence of the comparison made with Bonferroni correction, there was no statistically significantly difference between the weights of the rats on the 1 st and 7 th day $\mathrm{p}>0.025$ ). While there was no significant difference between the 1 st and 7 th days cases of the weight of the hepatectomy materials in the control group ( $p>0.025$ ), the weight of the cases of 7 th day hepatectomy materials statistically was significantly higher than the 1 st cases $(\mathrm{p}=0.012)$.

It was found that the 1st day detected mitosis number of the cases both in study and control group were higher than the 7 th day cases $(p=0.011)$. The 7 th day albumin levels of the cases in the control group were statistically significantly higher than the 1 st day albumin levels $(\mathrm{p}=0.018)$, however, there was no statistically significantly difference between the 1 st and 7 th days albumin levels of the cases in the study group $(p=0.324)$. When the number of the total bilirubin was compared, it was seen that there was no significant difference between the 1 st and 7 th cases of the control group ( $\mathrm{p}=0.944)$, but, the number of 1 st day total bilirubin was higher than the number of 7 th day total bilirubin $(p=.017)$.

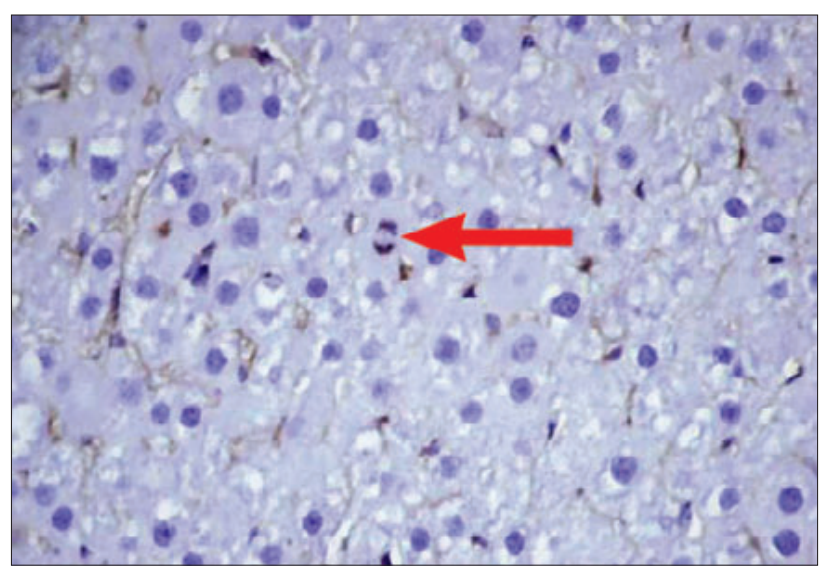

Fig. 6. x400 upsizing. Mitotic figures with arrow mark.

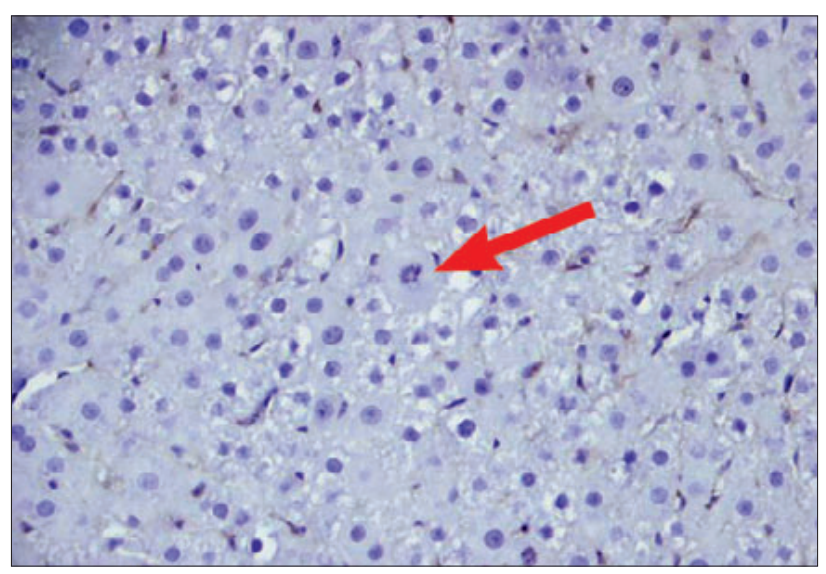

Fig. 7. x200 upsizing. Mitotic figures with arrow mark. 


\section{Discussion}

Liver is an organ, which has critical metabolic functions regarding all systems. Today, liver surgery can be performed in large centres because of both preoperative preoperative run-in and postoperative care and complications. Particularly, liver regeneration, which is the most important event after liver transplantation and better understanding of the factors effects this, will highly influence the models of recruitments (4).

It was shown that, regeneration in the liver tissue after partial hepatectomy begins from first day on (5-7). Functional liver recovering is completed in two weeks after the losing $2 / 3$ of the liver. Active cell replication begins within the first 24 hours after the partial hepatectomy and continues until the organ reaches its initial weight. Within 10 days, there occurs critical regeneration and this case is completed within 4-5 weeks. However, excised lobs don't take the same form of themselves. Instead, regeneration occurs with the formation of new lobules and expanding of remained lobules $(8,9)$. We didn't observe any significant difference between the 1st and 7th days hepatectomy weights of the cases in the control group ( $p>0.025)$. When the outcomes of the cases in the study group were examined, it was observed that the weight of the materials provided by the hepatectomy performed on the 7th day was statistically significantly higher than the hepatectomy materials provided on the 1 st day $(\mathrm{p}=0.012)$. As in Blaha et al article, significant liver weight increase is determined in liver tissue among the rats given carnitine in the same way after partial hepatectomy compared to the rats not given any carnitine (10).

Energy requirement for the liver regeneration is largely provided by lipolysis and fatty acids oxidation. Carnitine is an essential cofactor in metabolic changes and fatty acids oxidation developed after the partial hepatectomy. Among the rats in our experiment, there can be decrease in cartnitine biosyntheses after the partial hepatectomy because the liver is the only organ for the carnitine biosyntheses.

Serum transaminases sensitivity is very high at showing hepatocyte. Levels of the serum increase in all the conditions, in which the liver injury maintains as independent from aetiological factors. One of the most confident parameters in showing liver cell deterioration is ALT level (11). This occasion causes the levels of ALT and AST, which are measured after the partial hepatectomy performed in all the groups to be high. It was seen that these values dramatically reduce compared to the first day at the end of 7th day by the help of regenerative capacity of the liver.

When the levels of plasma albumin samples which were taken in 1st day of our study were compared, it was seen that the rats in the control group were statistically significantly higher than the rats in the study group $(\mathrm{p}=0.016)$. However, in terms of the levels of albumin, there was no statistically significant difference between the groups.

In the same way, there wasn't observed any statistically significant difference in the assessment of the outcomes of the 1st day in terms of the levels of total bilirubin $(p=0.340)$. Total bilirubin of the cases in the study group, which was given carnitine in 7 th day was statistically significantly lower than the control group, which didn't take carnitine $(\mathrm{p}=0.040)$. This result can be commented directly proportional with the following information: carnitine has strong toxic effects on organism and serves in conjugation of endogen or exogen acids $(12,13)$.

In the researches, many markers (DNA syntheses and mitosis number, volume of the liver, cell proliferation and mitochondrial activate) have been used to define the criterions of the liver regeneration (6). Gerdes et al identified the Ki-67 antigen and monoclonal antibody which was composed against the antigen in the cell nucleus (14). Ki-67 protein was identified in all the cell cycle (15). Antigen coverage increase as long as cell cycle keeps proceeding. It reached the highest level in G2-M phase. Monoclonal antibody, which was identified against Ki-67 antigen, has shown in all the phases except G0 phase of cell cycle. We used Ki-67 proliferation index as regeneration mitosis indicator.

After the examinations carried out by pathological clinic, detected mitosis number were examined. The 1 st and 7 th days mitosis number of the rats taken into the study was seen as statistically significantly higher than the mitosis number of the rats in the control group ( $p=0.020$ ). When 7 th day findings of the rat were examined, it was found that the mitosis number of the cases in the study group was statistically significantly higher than the cases in the control group ( $\mathrm{p}=0.001)$. Similarly, detected the mitosis number of the cases in 1st day in both study and control group was higher than the 7 th day cases $(\mathrm{p}=0.011)$. The increase in liver mass was statistically significantly higher among the rats given carnitine and in the same way the mitosis number in the group which is given carnitine was statistically significantly higher than the control group and this outcomes showed us that carnitine increased the liver regeneration.

Early studies about the effect of carnitine to liver regeneration indicated that the positive effect of carnitine on liver DNA syntheses depended on dose. Bohles (1987) and Blaha et al (1989) showed in their articles that $40 \mathrm{mg} / \mathrm{kg}$ carnitine dose was effective in liver regeneration and this dose was given in the form of infusion 24-30 hours permanently. In the same study, we could see that among the rats which were performed carnitine infusion without hepatectomy, many liver cell was detected at S phase within 10 $\mathrm{mg} / \mathrm{kg}$ dose of carnitine, but there was decrease in DNA syntheses with a high dose like $200 \mathrm{mg} / \mathrm{kg}$. We carried out $100 \mathrm{mg} / \mathrm{kg} /$ day dose intraperitonel carnitine infusion and in accordance with the literature; we saw that liver regeneration increased significantly.

This impact is thought to be related with the inadequate energy generation with beta oxidation $(16,17)$. Bohles and Akçetin showed in their studies that fatty acids carntine conjugations increase with the treatment of high level dose carnitine and the carnitine acyl translocation or carnitine acylt transferase activate increased the transfer of them to the outside of the matrix (17). In the light of this information it could be said that the active substrates, which are necessary for beta oxidation decreased in the existing of the high level dose carnitine. Besides, high level dose carnitine can cause membrane damage at hepatocytes because of the detergent effect of fatty acids carnitine conjugates.

As a summary, it could be seen that carnitine (on condition that to be taken high level dose) may have a stimulant affect on 
liver regeneration among the rats, performed partial hepatectomy. Carnitine showed this effect (dependent on its role in intrahepatic fat metabolism) on both posthepatectomy period, prereplicative period and later replicative period (17). We argue in the light of these outcomes that after any case causing hepatic surgery or acute injury of liver, it can be useful to add proper dose carnitine to the treatment in order to support patients in terms of nutritional.

\section{Results}

Liver regeneration, which is the most important period that occurred after liver surgery performed for any purpose or composed liver injury is a vital matter which has still been researched.

Factors initiating, maintaining and stopping the liver regeneration are identified to a large extent. But studies related regeneration capacity increase and/or fastening of the regeneration continue. In the studies which inspires our studies examined the effects of Lcarnitine on liver regeneration due to the metabolic properties of this carnitine. As it is known, carnitine is an essential cofactor in fatty acid metabolism and regenerate liver uses particularly fatty acids as energy source.

Among the rats which were applied hepatectomy, if met by the major conditions triggering liver regeneration following the external carnitine supplementation, we can say with the help of the information provided by the study measuring the regeneration capacity by analysing Ki-67 proliferation index that external carnitine support can increase the capacity of regeneration if it is given in appropriate dose.

\section{References}

1. Higgins GM, Anderson RM. Experimental pathology of the liver. Restoration on the liver of the white rat following surgical removal. Arch Pathol 1931; 12: 186-202.

2. Martins PNA, Theruvath TP, Neuhaus P. Rodent models of partial hepatectomies. Liver Int 2008; 28: 3-11.

3. Vanden Broek MA, Olde Damink SW, Dejong CH et al. Liver failure after partial hepatic resection: definition, pathophysiology, risk factors and treatment. Liver Int 2008; 28: 767-780.
4. Burke A, Lucey MR. Non-alcoholic fatty liver disease, non-alcoholic steatohepatitis and orthotopic liver transplantation. Am J Transplant 2004; 4: 686-693.

5. La Brecque DR, Feigenbaum A, Bachur NR. Diurnal rhytm: Effects on hepatic regeneration and hepatic regenerative stimulator substance. Science 1978; 199: 1082-1084.

6. Xu HS, Rosenlof LK, Jones RS. Bile secretion and liver regeneration in partially hepatectomized rats. Ann Surg 1993; 218: 176-182.

7. Schaffner F. Structural and functional aspects of regeneration of human liver. Dig Dis Sci 1991; 36: 1282-1286.

8. Michalopoulos GK, DeFrances MC. Liver regeneration. Science 1997; 276: $60-66$

9. Fausto N, Webber EM. Liver regeneration. In: Arias I, Boyer J, Fausto $\mathrm{N}$ et al (Eds). The liver:biology and pathobiology. New York: Raven Pres; 1994: 1059-1084.

10. Blaha V, Šimek J, Zivný P, Sobotka L. Effect of parenteral administration of carnitine on liver regeneration in partially hepatectomized rats. Physiol Bohemoslov 1990; 39: 233-242.

11. Hamanoue M, Kawaida K, Takao $S$ et al. Rapid and marked induction of hepatocyte growth factor during liver regeneration after ischemic or chrush injury. Hepatology 1992; 16: 1485-1492.

12. Belli M, Battelli D, Guarriero DM. Changes in mitochondrial activity caused by ammonium salts and the protective effect of carnitine. Biochem Biophys Res Commun 1989; 158: 181-188.

13. Tao RC, Peck GK, Yoshimura NN. Effect of carnitine on liver fat and nitrogen balance in intravenously fed growing rats. J Nutr 1981; 111: 171-177.

14. Gerdes J, Lemke H, Barsch H, Wacker HH, Schwab U, Stein H. Cell cycle analysis of a cell proliferation associated human nuclear antigen defined by the monoclonal antibody Ki-67. J Immunol 1984; 133: 1710-1715.

15. Gerdes J, Schwab U, Lemke H, Stein H. Production of a Mouse monoclonal antibody reactive with a human antigen associated with cell proliferation. Int J Cancer 1983; 31: 13-20.

16. Böhles H. Status of carnitine in clinical nutrition. An explanatory trial. Infusionsther Klin Ernahr 1987; Suppl 3: 33-36.

17. Böhles H, Akcetin Z. Ketogenic effect of low and high levels of carnitine during total parenteral nutrition in the rat. Am J Clin Nutr 1987; 46: $47-51$. 